\title{
Flexible Distribution Design in Microgrids for Dynamic Power Demand in Low-income Communities
}

\author{
Jimmy Ehnberg \\ Helene Ahlborg \\ Elias Hartvigsson
}

\author{
Dept. of Energy and Environment \\ Chalmers University of Technology \\ Gothenburg, Sweden \\ Corresponding author: jimmy.ehnberg@chalmers.se
}

\begin{abstract}
Microgrids for electricity provision have an important role to play in achieving current international targets of electrifying poor rural communities around the world. In the East-African context, microgrid developers face challenges related to dispersed settlement patterns and high poverty levels that prevent many rural citizens from affording grid connection. Contextual factors influence demand for electricity, leading to uncertainties regarding development of consumption in newly electrified areas. Developers usually oversize the system in anticipation of growing demand, which leads to significant investment costs and economic risk in case projected growth fails to appear.

Our focus in this paper is to introduce a concept of flexible distribution design - a process that can reduce initial investment cost and still be able to meet the long-term variations of the load, thereby reducing economic risks involved in microgrid development and thereby an entry barrier. We exemplify the usefulness of this design approach by seven steps of transfer capacity increase, which can be taken in sequence or in part, to achieve a distribution system configuration flexible enough to handle changes in electricity consumption, both increasing and in some cases also decreasing. Considerations on how flexible design would impact on system operation, power transfer capacity and demands on local technical expertise and maintenance are included. Importantly, the technical discussion is related to socioeconomic aspects and the consequences for end-users as well as the utility. Real-world examples of application of the mature technologies from East-Africa address the feasibility and provide a context for the discussion.
\end{abstract}

Index Terms- Load flow, distribution system, lines, compensation, Smart grids.

\section{INTRODUCTION}

As of today one billion people lack access to electricity around the world. Roughly half of these people live in subSaharan Africa, and a large majority of them live in rural areas [1]. Improving electricity access for these people is considered an important means towards combating extreme poverty. The importance of energy for development has been increasingly acknowledged. Energy access was not explicitly part of the Millennium Development Goals, but Goal 7 of the new Sustainable Development Goals is to: "Ensure access to affordable, reliable, sustainable and modern energy for all". According to UNDP, access to energy services can be "an important instrument in helping promote economic growth, social equality, and environmental sustainability" [2]. Evidence from sub-Saharan Africa shows that where access to electricity is provided, there have been substantial social benefits - related to illumination, education, health, leisure and security - and in some instances also economic development $[3,4,5]$. However, electricity provision is not in itself a sufficient condition for economic development of rural areas $[6,7,8]$.

The increased electricity access in developing countries has mainly been achieved through grid extension. Grid extension has led to a focus on communities close to the grid or larger urban areas, excluding large parts of the populations that live in rural areas due to the relatively high cost of the distribution system in relation to the expected load. In rural communities without access to the grid, kerosene and candles are commonly used for illumination, machinery is powered by diesel generators and radios run on dedicated batteries. If these communities are to gain the benefits of electricity access within the foreseeable future, off-grid solutions are needed [1,9-12].

Off-grid solutions come in various sizes - ranging from a few W of small Solar Home Systems (SHS), to diesel generator sets of a few $\mathrm{kW}$, and hydro power installations with generation capacity of several hundreds of $\mathrm{kW}$. SHS are becoming increasingly affordable for the higher income segment of the rural population, but the capacity is typically limited to supply a few low consuming appliances such as: illumination, radios and charging of phones. SHS provide important services but are of limited use for economically productive activities requiring machinery. Diesel generator sets can on the other hand supply enough power and energy to be used for productive activities such as: milling, workshops, irrigation pumps, welding and shops/bars, but are often too expensive for individual households or small businesses.

Microgrids (often ranging between 200-2000 users) are large enough to supply productive activities with power. The upfront investments (connection cost and electric appliances) and operation cost (tariff) required per individual user are often relatively affordable. However, the capital investment required for constructing the production and distribution system can be significant and difficult to finance for local investors.

A large-scale dissemination of microgrids has been hindered by several challenges associated with off-grid 
electrification, including: low household affordability, dispersed population, lack of sufficient subsidies, lack of supporting policies and institutions [9, 13]. Also, loads develop in different ways and in different paces, making sizing of microgrids very hard [14]. Developers usually oversize the system in anticipation of growing demand, which leads to significant investment costs and economic risk in case projected growth fails to appear. As a consequence of these factors, many utilities have struggled to reach cost-recovery, making microgrids economically unattractive for investors [15$18]$.

One way to reduce financial risks associated with microgrid development is to build flexible systems that can follow the development of the load and thereby the development of local communities. Flexibility is needed in all parts of the electric power system, from production, transmission and distribution to the user side. In the following, we focus on flexibility in the power transfer capacity of the distribution system. The target groups of this paper are donors, project managers and design engineers for microgrids to inspire them to think in another way.

The key argument in this paper is that there are mature technical solutions to build more flexible grids available. Flexible approaches are currently underutilized but have potential to lower financial risks working as entry barriers for microgrids in low-income communities. The challenge of adopting flexible distribution design is not primarily a technical one, but a matter of thinking out of the box.

The purpose of this paper is to present an example of a feasible strategy that would allow power transfer capacity to be made more flexible and to discuss the consequences of such flexibility. The focus is on power transfer capacity of medium voltage distribution systems, either via lines or other networks.

\section{FLEXIBLE DISTRIBUTION GRIDS}

A flexible grid is a grid that has the possibility to meet different and changing electricity consumption. We argue that the initial system should be small and have a low installation cost, and not imply any lock-in effects. The challenge is to be able to develop the system according to need for increased capacity without ending up in technical or other lock-ins. Also, it should be possible to reduce capacity in order to: use the installation for other purposes; to lower operation costs; reduce losses; or extend the expected lifetime of a certain component. These requirements will put new or different demands on utilities, and possibly also on funders as such flexibility may require different business models.

\section{STEPS OF DEVELOPMENT IN POWER TRANSFER CAPACITY}

The strategy is based on arrangement of well-established electricity transmission technologies, here called steps. Some of the steps include some minor modifications from conventional applications as to avoid lock-in. In this paper, the steps are arranged in an order that increases the capacity, but all may not be needed and some can be skipped if considered unsuitable or impossible to implement due to local conditions. The steps are also arranged such that they minimize the negative impact on (or require action or change of lifestyle of) customers. Some of the transitions between steps are reversible but not all.

Table 1 presents the steps of the development in power transfer capacity. For each step there is a short technical description of the transmission capacity and cost for equipment so far in the development. These are estimated in relation to the reference case of three phase (case D). The direct implications of each step for the utility and customers are summarized in the table and discussed in section VI and VII. We assume a constant number of customers, but discuss the option of an increasing number of customers in section VII. In the following section, we describe each step in more detail.

\section{DESCRIPTION OF THE STEPS}

\section{A. Manual transport of batteries}

The first, and the most basic, step of the strategy on electricity transfer is based on batteries being transported between a charging station and the place of use. Such a system is described in [19]. The figures in Table 1 are based on 100 batteries being charged every second day. Only the cost of batteries [19] is included in the estimated equipment cost. The life time of this kind of system is short due to the relatively short expected life time of batteries. When the utility develops the system from step A to B, the batteries may not be used. Still, the relatively low cost of batteries, their short life time and the possibility of a second hand market imply that step A does not require significant investment, create a lock-in or high extra cost for the utility, even if it lasts only for a short period of time.

\section{B. Single wire earth return}

Single wire earth return (SWER) provides low cost solutions to power transfer at distribution level [20] when only limited power is needed, but it also creates a situation of lockin. SWER has successfully been used for decades worldwide [20]. This is due to the fact that for conventional SWER new equipment is needed and almost no components, except perhaps lines and insulators, can be reused in the following steps. To avoid lock-in, we suggest the poles etc. are built in a way that allows for upgrading the system, i.e. one can install up to two more lines on the same poles.

Table 1 is based on the limited transmission capacity of SWER and the cost of the equipment that allow an upgrade to a three phase system. This incurs a $50 \%$ higher cost [21] than a conventional SWER system, but it does not have the same lock-in effect and reduces investment cost at later steps.

\section{Two phase}

To upgrade the SWER with an additional conductor has only a minor positive impact on the transmission capacity, but it is a step in the development of transfer capacity. How the second conductor can be used depends on the supplying and receiving equipment. 


\section{Three phase}

This is the standard case [22] to which the other steps are compared.

\section{E. Reactive power compensation}

To fully use the potential of the line it is important to reduce any reactive power that is transmitted. The calculations are based on a shunt capacitor compensation to unity of a load with a power factor of 0.9 . The cost of the reactive power compensation might be lower or even negative (i.e. the utility gains money) since the compensation will also lower the losses along the line. The voltage profile will also be improved but the value of that is harder to estimate. This step is reversible since the compensation equipment can be moved.

\section{F. Dynamic line rating}

Dynamic line rating (DLR) is a strategy to use the extra capacity that can be utilized when the surrounding conditions are not the design condition that the system is normally built for, that is, worst conditions. Here, only wind chill improvement is accounted for. If larger temperature variations are expected, which is the case in some parts of East Africa, then the potential of DLR is significantly higher. However, DLR rating might require some kind of load control or load scheduling. Costs of DLR consist mainly of measurement equipment on the line, compensation to customers and load controlling equipment. This means that the step is reversible if the power demand decreases. The compensation to customers can stop and the load controlling equipment may be moved.

\section{G. Demand side management}

The power transfer capacity of a line can be used more efficiently by controlling the load, because it introduces a more even distribution of power demand and that is called Demand side management (DSM). Table 1 is assuming the load situation described in [14] which is measured in a small village in rural Tanzania supplied via a microgrid. The most suitable order of DLR and DSM may be different depending on the local conditions. Costs of DSM are load controlling equipment. This means that the step is reversible if the power demand decreases. The compensation to customers can stop and the load controlling equipment may be moved.

Table 1. The different steps and their impact on transmission capacity, equipment cost, utility and customer usage. The usage perspectives are only summarized in the table.

\begin{tabular}{|c|c|c|c|c|c|}
\hline No. & Step & $\begin{array}{l}\text { Transmission } \\
\text { capacity [p.u.] }\end{array}$ & $\begin{array}{l}\text { Cost } \\
\text { [p.u.] }\end{array}$ & Utility usage perspective & Customer usage perspective \\
\hline A & Manual transport & $0,005[19]$ & 0,05 [19] & $\begin{array}{l}\text { Low investment cost; relatively simple } \\
\text { management and technical skills required; low } \\
\text { loads limit incomes }\end{array}$ & $\begin{array}{l}\text { Basic electricity use at affordable cost; } \\
\text { limited capacity; interruption in supply; } \\
\text { need for transport }\end{array}$ \\
\hline $\mathrm{B}$ & SWER & $\sim 0.33[22]$ & $0.68[22]$ & $\begin{array}{l}\text { Capacity increase: load monitoring required; } \\
\text { need for training of operators; still limited } \\
\text { incomes }\end{array}$ & $\begin{array}{l}\text { Limited capacity; non-interrupted supply } \\
\text { in-house via grid }\end{array}$ \\
\hline $\mathrm{C}$ & Two phase & $\sim 0.57[22]$ & $0.86[22]$ & $\begin{array}{l}\text { Additional cost for little extra capacity; } \\
\text { requires training of operators }\end{array}$ & $\begin{array}{l}\text { Capacity increase; allows more users or } \\
\text { slightly higher loads }\end{array}$ \\
\hline $\mathrm{D}$ & Three phase & $1[\mathrm{i}]$ & $1,05[22]$ & $\begin{array}{l}\text { Capacity increase; allow higher loads and } \\
\text { productive uses; can generate new income }\end{array}$ & $\begin{array}{l}\text { Capacity increase; allows for productive } \\
\text { uses and important income-generating } \\
\text { activities }\end{array}$ \\
\hline $\mathrm{E}$ & $\begin{array}{l}\text { Reactive power } \\
\text { compensation }\end{array}$ & 1.1 & $1.054[23]$ & $\begin{array}{l}\text { Capacity increase; allow for more customers; } \\
\text { improved stability of voltage }\end{array}$ & $\begin{array}{l}\text { Capacity increase; allows more customers; } \\
\text { improved quality of service }\end{array}$ \\
\hline $\mathrm{F}$ & DLR & Up to $2[24]$ & $1.054^{*}$ & 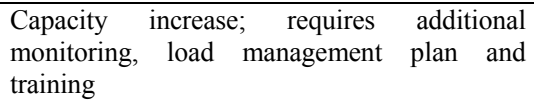 & $\begin{array}{l}\text { Conditioned capacity increase; load } \\
\text { management according to agreement }\end{array}$ \\
\hline $\mathrm{G}$ & DSR & 1.33 & $1.054 *$ & $\begin{array}{l}\text { Better use of available capacity; requires } \\
\text { agreement and enforcement of rules }\end{array}$ & $\begin{array}{l}\text { Increased conditioned capacity increase ; } \\
\text { requires agreement and compliance to rules }\end{array}$ \\
\hline
\end{tabular}

* The additional costs are very small or unknown because they are highly dependent on available load.

\section{IMPLICATIONS FOR THE UTILITY}

\section{A. Manual transport}

To operate a system for charging and transporting batteries will enhance the utility's knowledge about electricity uses in the area and thereby provide information on requirements for further development necessary before any large investments are undertaken. However, there will be very limited productive use of electricity given the limited capacity. The system can be rapidly built at a relatively small cost. The lifetime of the system is, in comparison with the other steps, short, and reinvestments will be needed every few years. The stage can be used to evaluate electricity use and demand and thereby offer prediction of demand before the next step is taken. Special competence on battery handling is required to avoid early decay of the battery.

\section{B. Single wire earth return}

SWER increases the capacity significantly compared to the previous step, but it will be a weak system that requires monitoring to avoid overload. It will require special training of the operators. The possibilities for productive uses of electricity are still very limited, resulting in limited income for the utility. 


\section{Two phase}

The addition of the extra conductor is an expensive step on the way to a three phase system, but it adds little capacity. It may be of interest under certain conditions. A complication of the two phase system is the need for upgrades of the equipment in the sending and receiving end of the network. This may be solved by series connection of two of the solution used for the SWER case. Operation of a two phase system is relatively unusually and therefore this step usually requires special training of operating staff.

\section{Three phase}

Step D is a standard system where standard methods for monitoring and standard equipment can be used.

\section{E. Reactive power compensation}

The step reduces the losses in the transmission system and increases the capacity. The compensation is based on installation of a static device (capacitor). The step requires some monitoring as to avoid over compensation or over voltage. This installation may also decrease the operating cost since the losses will decrease. The installation cost and the extra operating skills are relatively low.

\section{F. Dynamic line rating}

This step further increases the capacity available and thereby the transferred electricity increases. DLR must be locally adapted to the context. It will require monitoring of the line as to avoid overload. Also, action plans have to be put in place for situations when there is need to restrict loads. DLR may also utilize controllable loads to increase the utilization rate of the transmission in a way similar to that described for electricity production in [25]. Since DLR experience in real systems is low, in general and especially in this context, the utility needs to develop special operating procedures. The procedure has to be adapted to the specific context.

\section{G. Demand side management}

DSM has very similar implications for the utility as the DLR, but more focus has to be put on load control since it will be more frequently used. The business model also needs to be developed for a functioning DSM.

\section{IMPLICATIONS OF THE STEPS FOR CUSTOMERS}

\section{A. Manual transport}

A system with battery charging stations provides for small scale use such as charging of mobile phones, illumination, TV and radio. Loads that require constant power supply or high capacity to power machinery are not possible. Since the system is low voltage DC based some extra converting equipment may be needed. The need for transport to and from charging stations requires time and may result in extra costs for users. Step A allows users to access electricity at a small cost, benefit from cost savings and get used to electricity [26]. Thereby, this step lays the ground for the introduction of a more extensive system of higher capacity.

\section{B. Single wire earth return}

Step B provides for the same loads as step A, but allows for uses that require constant availability of electricity, e.g. refrigerators.

\section{Two phase}

Two phase avails more capacity in the system. More users can be connected, the same load is possible as before and there may be some capacity for productive uses (at a small scale).

\section{Three phase}

Three phase provides more capacity and customers can use electricity for productive uses, such as electric machinery in workshops and mills. There are cases where the utility or other actors offer various support to local entrepreneurs, resulting in positive economic development [27, 28].

\section{E. Reactive power compensation}

The step increases the capacity, which allows for more customers to be connected, or for customers to increase their use. The step also improves the stability of voltage supplied.

\section{F. Dynamic line rating}

Introduction of DLR increases the capacity, but not all the time. The load must be controlled occasionally, by prioritizing loads or disconnecting some users according to agreement.

\section{G. Demand side Management}

Step G offers a possibility to increase the capacity without adding installation costs, but it requires regulations and agreements between utility and users. Users must comply with rules or risk sanctions. DSM can be flexible and users have possibilities to influence regulations. Strong public support for DSM can also help minimize free-riding and facilitate enforcement [27].

Importantly, depending on the ownership and business model of the microgrid the relationship between the utility and its customers may differ significantly - including the priority given to commercial (high load) or non-commercial (small load) customers. For example, in the membership based and non-profit public utility in Mawengi, Tanzania, the objective has been to connect as many customers as possible (for social impact) while also supporting local businesses and productive activities (in order to raise sufficient incomes) [27]. The utility continues to connect households with very low use, and seeks to raise its income by other means, rather than only connecting high-use customers. As the peak load approached the maximum capacity of the utility, the trade-off between social impact and economic viability became more articulated. In response to prolonged drought and low water table in the river supplying the hydropower station, in 2013, the utility sat in meetings with milling machine owners (the largest loads) to introduce voluntary load control (step G). The measure successfully prevented overload and removed the need for load shedding. 


\section{CONCLUSIONS}

This paper has initiated a more in-depth discussion on technical and managerial options to increase flexibility and thereby reduce risk in microgrid development by arguing for creative thinking around development of transfer capacity based solely on mature technologies. We discuss the motivation for and consequences of increased flexibility for utilities and users. The paper demonstrate introduce the feasibility of flexible design through an example of a strategy of seven steps, which render the power transfer capacity of medium voltage lines more flexible. The steps are arranged in order to increase power transfer and some of the seven steps are reversible. The implication for the utility is that the initial investments are smaller and the capacity may grow with the demand, but productive uses may initially be limited. The technical skills of the operators will vary between steps and can build up as the system is developed. For users, this approach provides a stepwise and more affordable electricity access, with initially low capacity that can grow with the number of users and their increasing loads. Further work is required to address other aspects of distribution, e.g. robustness, as well as flexibility in the other parts of electric power systems

\section{REFERENCES}

[1] IEA, "World Energy Outlook," International Energy Agency. 2013

[2] UNDP, "Energizing the Millennium Development Goals," United Nations Development Programme, New York, 2005

[3] A. Ellegård, A. Arvidson, M. Nordström, O.S. Kalumiana and C. Mwanza, "Rural people pay for solar: experiences from the Zambia PVESCO project", Renewable Energy, 29, pp. 1251-63, 2004

[4] J. Peters, M. Harsdorff, and F. Ziegler, "Rural electrification: Accelerating impacts with complementary services", Energy for Sustainable Development, 13, pp. 38-42, 2009

[5] G. Åkesson, and V. Nhate, V. "Study on the socio-economic and poverty impact of the rural electrification project Ribáuè/Iapala, Nampula, Mozambique”, (Maputo: Swedish Embassy in Mozambique). 2006

[6] D. Barnes, The challenge of rural electrification: strategies for developing countries, Washington, DC: Routledge. 2007

[7] S. Bhattacharyya, "Rural Electrification through Decentralised Off-grid Systems in Developing Countries," Springer. 2013

[8] J. Goldemberg, T. B. Johansson, A. K. N. Reddy, and R. H. "Williams Basic Needs and Much More with One Kilowatt per Capita". Ambio, 14(4/5), pp. 190-200. 1985

[9] H. Ahlborg, and L. Hammar, "Drivers and barriers to rural electrification in Tanzania and Mozambique - Grid-extension, off-grid, and renewable energy technologies," Renewable Energy, 61, pp. 117-124, 2014.

[10]P. Díaz, C. A. Arias, R. Peña, and D. Sandoval, "FAR from the grid: A rural electrification field study," Renewable Energy, 35(12), 2010.

[11]B. Tenenbaum, C. Greacen, T Siyambalapitya, and J. Knuckles, "From the Bottom Up - How Small Power Producers and Mini-grids Can Deliver Electrification and Renewable Energy in Africa," The World Bank. 2014.
[12]J. Urpelainen, "Grid and off-grid electrification: An integrated model with applications to India," Energy for Sustainable Development, 19, pp. 66- 71, 2014.

[13]A. C. Brent, and D. E. Rogers, "Renewable rural electrification: Sustainability assessment of mini-hybrid off-grid technological systems in the African context," Renewable Energy, 35(1), pp. 257-265, 2010

[14]E. Hartvigsson, J. Ehnberg, E. Ahlgren and S. Molander "Assessment of load Profiles in Minigrids: A case in Tanzania", Proc. In 50th International Universities Power Engineering Conference, 2015

[15]GTZ (2010). Rural Electrification by Battery Charging Stations, [Online] Available https://energypedia.info/images/0/01/Rural_electrification_by_ battery_charging_stations.pdf

[16]C. Kirubi, A. Jacobson, D. M. Kammen, and A. Mills, "CommunityBased Electric Micro-Grids Can Contribute to Rural Development: Evidence from Kenya," World Development, 37(7), pp. 1208-1221, 2009.

[17]T. Levin and V. M. Thomas, "Utility-maximizing financial contracts for distributed rural electrification," Energy, 69(0), pp. 613-621. 2014

[18]D. Schnitzer, S. D. Lounsbury, J. P. Carvallo, R. Deshmukh, J. Apt and M.D. Kammen, "Microgrids for Rural Electrification: A critical review of best practices based on seven case studies", United Nations Foundation. 2014

[19]D. Barnes, and G. Foley,'Rural Electrification in the Developing World: A Summary of Lesson from Successful Programs". ESMAP, World Bank, 2004.

[20]N. Hosseinzadeh and J. Rattray, "Econmics of Upgrading SWER Distribution Systems" Australasian Universities Power Engineering Conference, 2008.

[21]R. W. Jarrett, A. M. T. Oo and B. Harvey, "An investigation into the use of four quadrant inverter devices for voltage and var support on SWER systems," Universities Power Engineering Conference, 2012

[22]R. Widmer and A. Arter Village electrification. Switzerland Part 6. Distribution systems St. Gallen, SKAT, 1992

[23]Energy market inspectorat (2015) Normvärdeslista elnät 2016-2019, [online] Available in Swedish, http://ei.se/Documents/Forhandsreglering el/2016-2019/Dokument/Normvardeslista_elnat_2016-2019.pdf

[24]A. Michiorri, H-M Nguyen, S, Alessandrini, J. B. Bremnes, S. Dierer, E. Ferrero, B-E. Nygaard, P. Pinson, N. Thomaidis, S. Uski, "Forecasting for dynamic line rating", Renewable and Sustainable Energy Reviews, vol 52, pp.1713-1730, December 2015.

[25]J. Ehnberg, “Autonomous Power Systems based on Renewables - On generation reliability and system control" Ph.D. dissertation, Energy and Environment, Chalmers University of Technology, Göteborg, 2007.

[26]K., Ulsrud, T. Winther, D. Palit and H. Rohracher, "Village-level solar power in Africa: Accelerating access to electricity services through a socio-technical design in Kenya”, Energy Research \& Social Science, 5, pp. 34-44. 2015

[27]H. Ahlborg, H. and M. Sjöstedt, "Small-scale hydropower in Africa: Socio-technical designs for renewable energy in Tanzanian villages," Energy Research \& Social Science, 5, 20-33. 2015

[28]UNDP, "Reducing rural poverty through increased access to energy services. A review of the Multifunctional Platform Project in Mali", United Nations Development Programme. 2004 